\title{
INFLUENCE OF CAGE SHAPES ON GROWTH AND PRODUCTION OF SILURID CATFISH (MYSTUS CAVASIUS) IN EARTHEN POND
}

\author{
M. H. Mithun' ${ }^{1}$, I. Rashid ${ }^{1}$, M. A. Salam ${ }^{2}$ and M. J. Alam ${ }^{\text {* }}$
}

\begin{abstract}
Influence of three cage shapes viz (i) rectangular ii) square, and (iii) circular on growth and production of Mystus cavasius (local name: gulsha) was studied in earthen pond conditions for a period of 120 days. Each of nine cages, which were made of polyethylene nets, had same internal area $\left(1.80 \mathrm{~m}^{3}\right)$ and stocked with $M$. cavasius fry at the rate of $300 \mathrm{~m}^{-3}$, following a completely randomized design. Fishes were fed with a commercial floating pellet feed (Mega 002) initially at the rate of $25 \%$ of average body weight, with a gradual reduction to $8 \%$. Significantly higher $(P<0.05)$ average weight gain $(\mathrm{AWG})$ of $13.49 \pm 0.14 \mathrm{~g}$, with specific growth rate (SGR) of $1.87 \%$ day $^{-1}$, and the survival rate of $89.41 \%$ were recorded for gulsha reared in the circular cage compared to the other shapes. Rectangular and square cages resulted in a similar $(P>0.05)$ AWG of $10.29 \pm 0.10$ and $10.43 \pm 0.25 \mathrm{~g}$ with survival rate of 80 and $83.61 \%$, respectively. A significantly higher $(P<0.05)$ average total production of $4.05 \pm 0.21 \mathrm{~kg} / \mathrm{m}^{3}$ was obtained with circular cage compared to a similar production of $2.72 \pm 0.28$ and 3.08 $\pm 0.29 \mathrm{~kg} / \mathrm{m}^{3}(P>0.05)$ in rectangular and square cages, respectively. In case of lengthweight relationship (LWR), the coefficient of determination values $\left(\mathrm{r}^{2}\right)$ was $0.86,0.90$, and 0.85 in square, circular and rectangular cages, respectively indicating a good linear regression between length and weight in circular cages than square and rectangular cages. Taken together, these results indicate that circular cage is the best for growth, survival and production of gulsha culture in pond condition.
\end{abstract}

Keywords: Net cage, fish culture, pond environment, Mystus cavasius, cage shape effects.

\section{Introduction}

Aquaculture is one of the most potential areas to meet the globally increasing demand for fish as food, nutrition, income, and livelihoods. Over last three decades, Bangladesh has made a revolution in aquaculture with a 25 -fold growth in farmed fish market. Within the last 10-12 years, the contribution of farmed fish to net fish output has grown from 43 to $56 \%$
(DOF, 2018), meaning that cultured fish now overtakes the volume of captured fish. Pondbased culture of major carps is the mainstay of fish production, while monoculture of a few exotic and native fish species is in practice. In the face of increasingly scarce productive land and water areas due to massive development works, further horizontal expansion of pondbased aquaculture is carrying a big challenge.

\footnotetext{
${ }^{1}$ Department of Fisheries Biology and Aquatic Environment, Faculty of Fisheries, Bangabandhu Sheikh Mujibur Rahman Agricultural University, Gazipur 1706, Bangladesh. ${ }^{2}$ Department of Genetics and Fish Breeding, Faculty of Fisheries, Bangabandhu Sheikh Mujibur Rahman Agricultural University, Gazipur 1706, Bangladesh.

*Corresponding Author: mjalam@bsmrau.edu.bd
} 
The research question has now been raised how to address this challenge through minimizing land usage and increasing demand of fish production. Diversified utilization of existing pond water resources for fish production may be considered as a focus area of research.

Among the different fish production systems, cage culture is one which is mainly practiced in open water bodies where fish utilizes water but remain enclosed in a cage allowing water to pass freely between the fish and surrounding environment. Closed ponds can also be used as potential site for cage culture provided that the water quality is suitable and there is adequate water depth beneath the cages to allow water movement (Soltan, 2016). Integration of inpond cage culture with open pond fish culture system may be a potential area of intervention not only for maximizing the resource utilization and increasing production, but also benefitting farmers with diversified crops and income. While cage fish culture is concerned, size and shape of cages play a key role in depending on the behavior of fishes. While circular shaped cages found to be the best for schooling fishes such as salmon, milkfish, the less active species such as the tilapia and common carp are found to be more particular with rectangular cages (Mukherjee, 1990).

Although a good number of report on cage culture of tilapia (Golder et al., 1996), common carp (Kohinoor and Rahman, 2013), and Mystus cavasius (Kohinoor and Rahman, 2015) in open flowing water system published, reports on cage culture of fishes in ponds such as Thai strain Anabas testudineus (Mondal et al., 2010); Clarias gariepinus and Nile tilapia (Mondal et al., 2014); Heteropneustes fossilis (Rahman et al., 2017) have been published. None of these reports addressed the effects of cage shapes except that of Hasan (2014), who reported relatively higher net yield of Heteropneustes fossilis in modified square shaped cage than that of ordinary and rectangular shaped cages.

The silurid catfish, Mystus cavasius is one of the small indigenous species native to Asian region. It has a highly promising cultured fish in the local environment due to high tolerance to crowded condition and high market value. However, no study has so far been conducted on culture of M. cavasius in cages in the ponds. Owing the significance and plausibility of cage culture in pond-based aquaculture system, the present study aimed to compare the suitability of three types of cages viz, rectangular, square and circular cages on growth and production of M. cavasius in the earthen pond.

\section{Material and Methods}

The present experiment was carried out in a closed earthen pond of the Faculty of Fisheries, Bangabandhu Sheikh Mujibur Rahman Agricultural University, Gazipur, Bangladesh for a period of 120 days from 2nd April to 1st August 2019.

\section{Experimental design}

The experiment was designed for three different shapes of (i) rectangular, (ii) square, and (iii) circular having a similar volume of $1.80 \mathrm{~m}^{3}$ with $1 \mathrm{~m}$ height. Each cage shape, hereinafter "treatment", had three replications and were assigned into a Completely Randomized Design. The fish species was a high valued threatened indigenous silurid catfish species $M$. cavasius, which is locally known as "gulsha". Each cage of three 
treatments was stocked with gulsha fry at the same rate of $300 \mathrm{~m}^{-3}$.

\section{Construction and installation of net cages}

The shape of each cage was made of colored iron bars, covering and tying with high density polyethylene net of about $1 \mathrm{~cm}$ mesh. The cages were placed in the pond fastening with bamboo platform and poles, maintaining distance from one cage to another about $1 \mathrm{~m}$. The heights of all the cages were uniformly raised to about $25 \mathrm{~cm}$ to expose from water surface and $50 \mathrm{~cm}$ from the pond bottom. One edge of the upper surface of each cage was kept tied with nylon threads in a way so that it could be opened for stocking fish, delivering feed and periodical sampling.

\section{Fish stocking in cages}

Overwintered gulsha fry of individual length and weight ranging from $3.75-4.50 \mathrm{~cm}$ and 1.50-2.00 g, respectively, were collected from a fish farm, transported to pond site and stocked 540 fish fry to each cage, according to the experimental design. Prior to stocking, fish were acclimatized to the pond water for about 30 minutes.

\section{Feeding}

The fish in all cages were fed with a commercial floating pellet feed (Mega 002). The proximate composition of fish feed, according to manufacturer (Spectra Fish Feed Ltd) is presented in (Table 1). Initially the fish were fed at the rate $25 \%$ of average body weight, which was gradually reduced to $8 \%$. Feeding adjustment was done every two weeks with the progressive increase in average body weight. Feed was applied twice a day at dawn and dusk.
Table 1. Proximate composition of the fish feed (according to Spectra Fish Feed Ltd.)

\begin{tabular}{cc}
\hline Components & \% composition \\
\hline Moisture & 12 \\
Protein & 36 \\
Lipid & 5 \\
Carbohydrate & 31 \\
Fiber & 5 \\
Ash & 10 \\
\hline
\end{tabular}

\section{Monitoring water quality and fish growth}

The water quality parameters such as temperature $\left({ }^{\circ} \mathrm{C}\right)$, dissolved oxygen $(\mathrm{mg}$ $\left.1^{-1}\right), \mathrm{pH}$, transparency $(\mathrm{cm})$ and ammonia (mg $^{-1}$ ) were recorded at weekly interval, inside and outside the cages, throughout the experimental period at 9.00-10.00 hours using centigrade thermometer, portable DO meter (Model Lutron PDO-519), portable $\mathrm{pH}$ meter (HANNA HI 8424), Secchi disc, and Ammonia test kit (Freshwater, HANNA), respectively.

The fish $(\mathrm{n} \approx 25)$ from all cages were collected using a scoop net for measuring individual length $(\mathrm{cm})$ and weight $(\mathrm{g})$ at fortnight interval. Standard wooden measuring board and portable digital balance (Denver-xp-3000) were used to measure length and weight, respectively.

\section{Harvesting and estimation of yield parameters}

After 120 days of culture period, treatmentwise cages were lifted from the water and fish were harvested by scoop net and hand picking. The individual length $(\mathrm{cm})$ and body weight (g) of fish $(\mathrm{n} \approx 60)$ and number of harvested fish were recorded for estimating different yield parameters as follows: 
a) Survival rate $(\%)=$ Number of fish stocked $\div$ Number of fish harvested $\times 100$

b) Specific growth rate (SGR, \%day $\left.{ }^{-1}\right)$ $=[\ln ($ final weight $)-\ln ($ initial weight $)$ $\times 100]$ / No. of days of the experiment

c) Final weight gain $(\mathbf{g})=$ Final individual weight - Initial individual weight

d) Average daily gain (ADG, g/day) = Mean final weight - Mean initial weight $\div$ Culture days

e) Feed conversion ratio $(\mathbf{F C R})=$ Feed applied (dry weight)/ Live weight gain

f) Net production $\left(\mathbf{k g} / \mathbf{m}^{\mathbf{3}}\right)=$ total biomass at harvest - total biomass at stocking

\section{Length-weight relationship (LWRs)}

The measured length and weight of fish of each treatment at harvest were subjected to estimate length-weight relationships (LWRs).

The log transformation formula of Le Cren was used to establish LWRs (Le Cren, 1951). A simple linear relationship in the form of $\mathrm{Y}=$ $(\mathrm{a}+\mathrm{bX})$ exists between two length dimensions of fish where "Y" is Log Body Weight (BW) and " $X$ " is Log Total Length (TL). The relationship between length and weight in fisheries biology is usually calculated by the following equation (Le Cren, 1951):

$$
\mathrm{W}=\mathrm{a} \mathrm{L} \mathrm{b}
$$

Where, $\mathrm{W}=$ Body weight of fish

$$
\begin{aligned}
& \mathrm{L}=\text { Linear measure of the fish length } \\
& \mathrm{a}=\text { Intercept (Constant) } \\
& \mathrm{b}=\text { an exponent (Slope) }
\end{aligned}
$$

The slope "b" of the linear equation was estimated as:

$$
\mathrm{b}=[\mathrm{n} \Sigma \mathrm{XY}-\Sigma \mathrm{X} \Sigma \mathrm{Y}] /[\mathrm{n} \Sigma \mathrm{X} 2(\Sigma \mathrm{X}) 2]
$$

The intercept, a, was calculated by: $a=Y-b X$.

To estimate the correlation coefficient, $r$, the following formula was used as:

$$
\begin{aligned}
& \mathrm{r}=[\mathrm{n} \Sigma \mathrm{XY}-\Sigma \mathrm{X} \Sigma \mathrm{Y}] / \sqrt{ }([\mathrm{n} \Sigma \mathrm{X} 2-(\Sigma \mathrm{X}) \\
& \text { 2] }[\mathrm{n} \Sigma \mathrm{Y} 2-(\Sigma \mathrm{Y}) 2])
\end{aligned}
$$

The coefficient of determination, $r^{2}$ or the square of the correlation coefficient showed the proportion of the variability in the $\mathrm{Y}$ observations which could be assigned by the variability in the $\mathrm{X}$ observations.

\section{Data analysis}

All the data collected during experiment were recorded and preserved on a computer spreadsheet. Growth and yield parameters of fish were analyzed statistically by oneway ANOVA) using the statistical software (Statistix 10). If a main effect was significant, the ANOVA was followed by DMRT (Duncan Multiple Range Test) at 5\% level of significance. The length-weight data were subjected to regression analysis for estimating 95\% Confidence Interval (CI) of a and $\mathrm{b}$, and the coefficient of determination $\left(\mathrm{r}^{2}\right)$. All statistical analyses were considered significant at $p<0.05$.

\section{Results and Discussion}

The water quality parameters showed variations during the culture period, but were similar $(P>0.05)$ and noted within the recommended range for the growth performance of cultured fish (Bhatnagar and Garg, 2000). The mean temperature, dissolved oxygen, $\mathrm{pH}$, transparency, and ammonia, inside and outside the cages, are presented in (Table 2). The average water temperature was higher during the experimental period of summer months, but did not affect the fish. 
Table 2. Mean and range values of water quality parameters inside and outside of cages during the experimental period of 120 days

\begin{tabular}{lccccc}
\hline \multirow{2}{*}{ Water quality parameters } & \multicolumn{2}{c}{ Outside cages } & & \multicolumn{2}{c}{ Inside cages } \\
\cline { 2 - 3 } \cline { 5 - 6 } & Mean \pm SD & Range & & Mean \pm SD & Range \\
\hline Water Temperature $\left({ }^{\circ} \mathrm{C}\right)$ & $32.90 \pm 1.55$ & $31.40-34.50$ & & $32.90 \pm 1.55$ & $31.40-34.50$ \\
$\mathrm{pH}$ & $7.80 \pm 0.11$ & $7.69-7.90$ & & $7.50 \pm 0.20$ & $7.30-7.70$ \\
$\mathrm{DO}\left(\mathrm{mg} \mathrm{l}^{-1}\right)$ & $5.50 \pm 0.38$ & $5.10-5.90$ & & $5.10 \pm 0.60$ & $4.50-5.70$ \\
Transparency $(\mathrm{cm})$ & $35.10 \pm 1.20$ & $33.90-36.30$ & & $35.80 \pm 1.20$ & $34.60-37$ \\
Total ammonia $\left(\mathrm{mg} \mathrm{l}^{-1}\right)$ & $0.10 \pm 0.05$ & $0.05-0.15$ & & $0.18 \pm 0.08$ & $0.10-0.26$ \\
\hline
\end{tabular}

The initial weight, harvest weight, weight gain, average daily weight gain (ADWG), specific growth rate (SGR), survival and gross yield of gulsha are presented in Table 3. The survival rate of gulsha was $83.61 \pm 3.10 \%, 89.44 \pm 4.30 \%$, and $80.21 \pm 5.40 \%$ in square, circular, and rectangular shaped cages, respectively, with significant differences among the treatments $(P<0.05)$. The survival rate of gulsha in the present experiment, irrespective to the test shapes of cage, was higher compared to that has been reported $(52-66 \%)$ for the same species reared in rectangular shaped cages in open water (Kohinoor and Rahman, 2015). Survival rates of $98.67 \%$ in climbing perch (Anabas testudineus) and $86.67 \%$ in tilapia (Mondal et al., 2010); 29 to $55.30 \%$ in African catfish (Clarias gariepinus) and 75.50 to $86.10 \%$ in tilapia (Mondal et al., 2014) have been reported in pond-cage culture system.

The circular shaped cages resulted in significantly higher survival, while the rectangular and square shaped cages had a more or less similar rate of survival and comparatively lower than the circular shaped cages.

Gulsha grew steadily in circular shaped cage at about $0.11 \mathrm{~g}$ day $^{-1}$ during the entire culture period and reached an average final weight of
$15.09 \mathrm{~g}$ with significant difference $(P<0.05)$ compared to square and rectangular shaped cages where the average final weight was $12.27 \mathrm{~g}$ and $11.92 \mathrm{~g}$, respectively (Table 3; Fig. 1). There were no significant differences in incremental as well as in final weight gain in gulsha between rectangular and square cage treatments $(P<0.05)$. The average daily weight gain in gulsha in all treatments was within the range of 0.001 to 0.517 for the same species, but cultured in cemented tanks on different diets (Fatema et al., 2017).

The specific growth rate (SGR) of gulsha ranged from 1.52 to $1.87 \%$ day $^{-1}$ with progressively a declining rate (Table 3 ; Fig. 2). The SGR of gulsha in circular cage treatment was significantly higher $(P<0.05)$ than those of gulsha in rectangular and square cage treatments.

The SGR of gulsha in the present experimental condition was much lower that has been reported (4.80 to $5.50 \%$ day $\left.^{-1}\right)$ for 210 days of monoculture (All Hosen et al., 2017), but more or less similar than that has been reported (1.56 to $1.75 \%$ day $^{-1}$ ) for 180 days of polyculture of the same species in earthen ponds (Kohinoor et al., 2011-12). The SGR of climbing pench and Nile tilapia reared in 


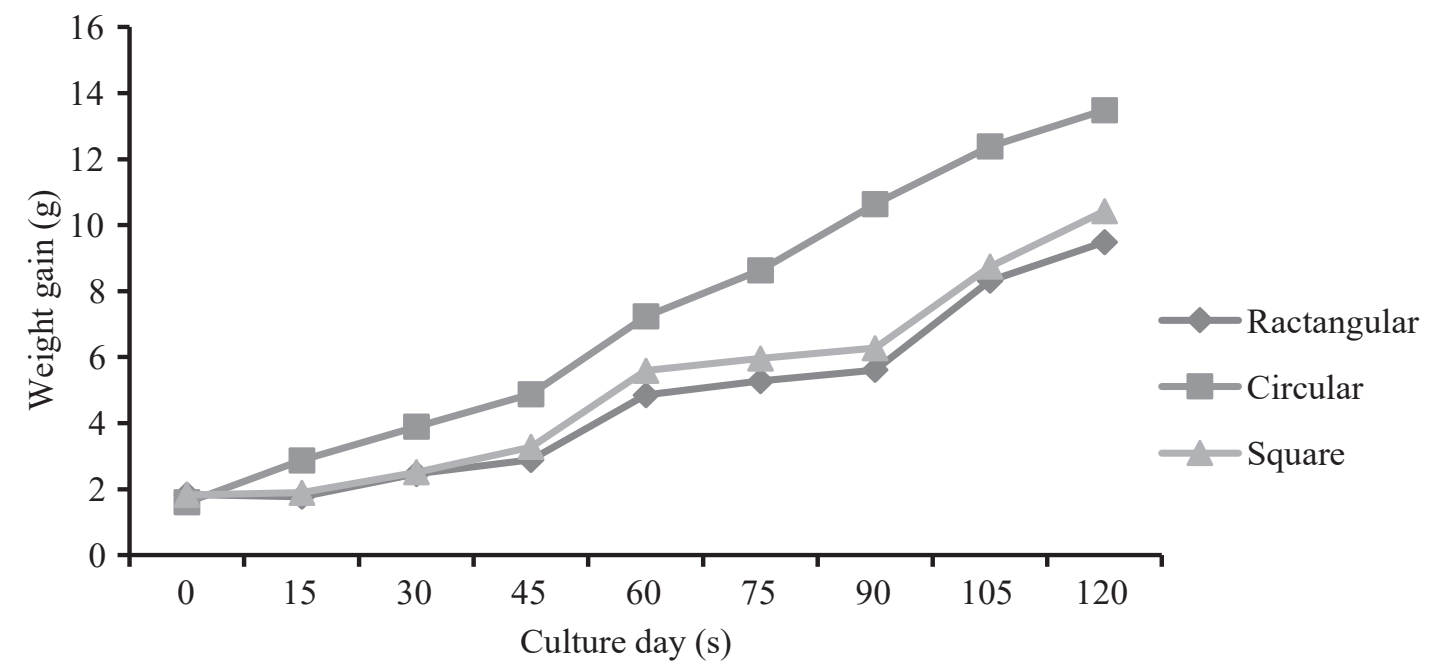

Fig. 1. Growth of gulsha in different shape of cages during the experimental period of 120 days.

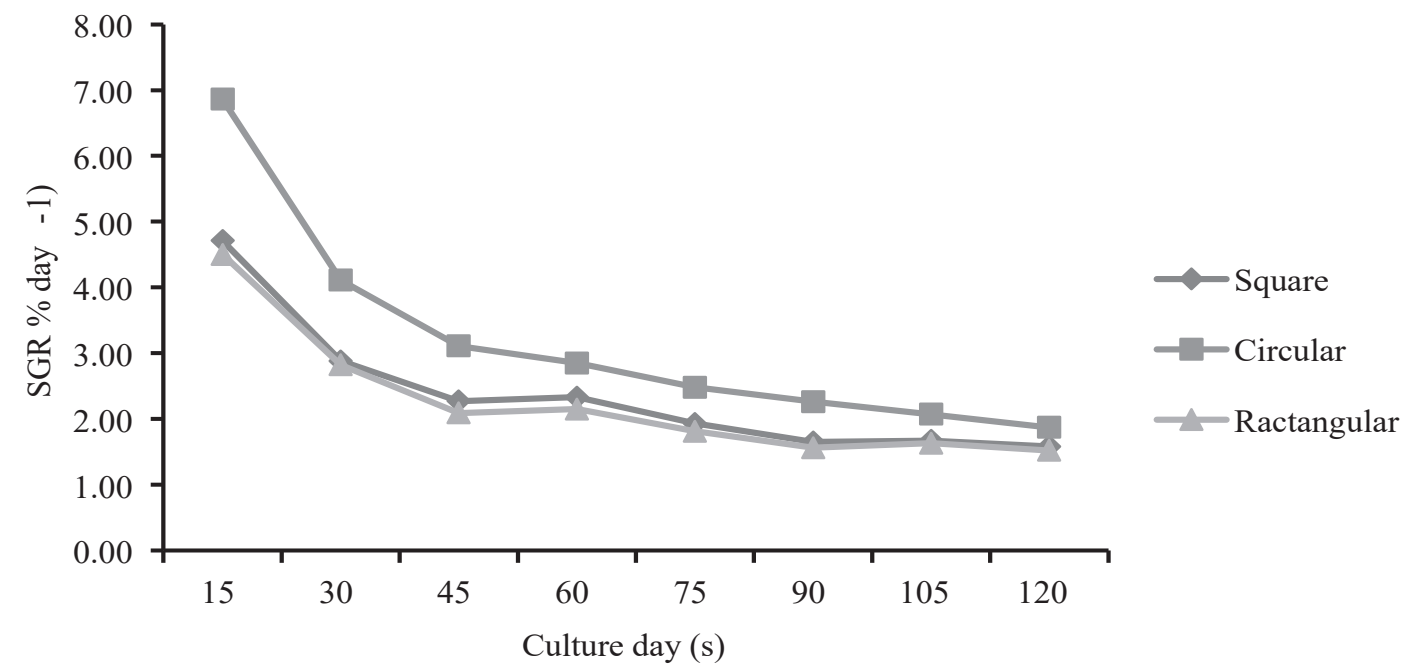

Fig. 2. Specific growth rate (SGR) of gulsha in different shape of cages during the experimental period of 120 days.

cages in pond has been reported as 1.17 and $1.15 \%$ day $^{-1}$ for 120 days of culture period (Mondal et al., 2010), which is lower than the SGR of gulsha in the present experiment.

The mean values of FCR were significantly different $(P<0.05)$ among the treatments (Table 3). The lowest FCR value of 1.90 was observed in circular cage treatment and the highest FCR value of 2.69 in square cage. In this study, the FCR was comparatively lower compared to the values of 2.46 to 3.04 which has been reported by Kohinoor and Rahman (2015) in case of cage culture of the same species in open water. 
Corresponding to higher growth and survival, circular cage treatment resulted in the significantly higher $(P<0.05)$ gross mean production of $4.05 \mathrm{~kg} / \mathrm{m}^{3}$ and net production of $3.62 \mathrm{~kg} / \mathrm{m}^{3}$ for 120 days of culture period (Table 3 ). The mean gross production rate of gulsha in rectangular and square cage treatments were $2.72 \mathrm{~kg} / \mathrm{m}^{3}$ and $3.08 \mathrm{~kg} / \mathrm{m}^{3}$, respectively and the net production were 2.47 $\mathrm{kg} / \mathrm{m}^{3}$ and $2.62 \mathrm{~kg} / \mathrm{m}^{3}$ without any significant difference. Kohinoor and Rahman (2015) reported a production rate of $8.14 \mathrm{~kg} / \mathrm{m}^{3}$ of gulsha at $500 \mathrm{fry} / \mathrm{m}^{3}$ stocking density for a culture period of 210 days in rectangular cages in open water environment. Considering the culture period and stocking density of the present experiment and that of Kohinoor and Rahman, (2015), it could be said the gulsha yield in circular cages in the present experimental condition was higher than that in rectangular cages in open water conditions The overall experimental results of the present study demonstrated that the highest growth, survival and production in the circular cage might be possibly attributed due to its shape, which provided suitable environment to manipulate the schooling behavior of this catfish species. The highest survival (89.44\%) and lowest FCR (1.90) in circular cage treatment indicates that there was less stress of fish for movement that the fish encountered in rectangular and square cages due to their schooling in bottom corners.

In aquaculture, cage can be of any shape but rectangular, square or cylindrical shapes are typical (Soltan, 2016). The suitability of shape of an enclosure depends on behavior of the culture species and their movement preference in the culture medium. The fish species that have the habit to move in a rotary motion with schooling, enclosure with rounded corners, or circular, sometimes hexagonal serves the purpose better in place of rectangular one

Table 3. Growth and production performance of $M$. cavasius in different treatments during the 120 days of culture period

\begin{tabular}{lccc}
\hline \multirow{2}{*}{ Parameter } & \multicolumn{3}{c}{ Shape of the Cage } \\
\cline { 2 - 4 } & Square & Circular & Rectangular \\
\hline Initial Length $(\mathrm{cm})$ & $4.20 \pm 0.30$ & $3.97 \pm 0.21$ & $4.07 \pm 0.15$ \\
Final Length (cm) & $12.64 \pm 0.25^{\mathrm{b}}$ & $15.80 \pm 0.09^{\mathrm{a}}$ & $11.80 \pm 0.19^{\mathrm{c}}$ \\
Initial Weight (g) & $1.83 \pm 0.06^{\mathrm{a}}$ & $1.60 \pm 0.10^{\mathrm{b}}$ & $1.83 \pm 0.06^{\mathrm{a}}$ \\
Final Weight (g) & $12.27 \pm 0.25^{\mathrm{b}}$ & $15.09 \pm 0.05^{\mathrm{a}}$ & $11.32 \pm 0.22^{\mathrm{c}}$ \\
Weight Gain (g) & $10.43 \pm 0.25^{\mathrm{b}}$ & $13.49 \pm 0.14^{\mathrm{a}}$ & $10.29 \pm 0.10^{\mathrm{c}}$ \\
SGR (\% day-1) & $1.58 \pm 0.03^{\mathrm{b}}$ & $1.87 \pm 0.05^{\mathrm{a}}$ & $1.52 \pm 0.03^{\mathrm{b}}$ \\
ADWG (g) & $0.09 \pm 0.00^{\mathrm{b}}$ & $0.11 \pm 0.00^{\mathrm{a}}$ & $0.08 \pm 0.00^{\mathrm{c}}$ \\
Survival (\%) & $83.60 \pm 6.10^{\mathrm{b}}$ & $89.40 \pm 4.30^{\mathrm{a}}$ & $80.21 \pm 8.40^{\mathrm{c}}$ \\
Gross Production $\left(\mathrm{Kg} / \mathrm{m}^{3}\right)$ & $3.08 \pm 0.29^{\mathrm{b}}$ & $4.05 \pm 0.21^{\mathrm{a}}$ & $2.72 \pm 0.28^{\mathrm{b}}$ \\
Net Production $\left(\mathrm{Kg} / \mathrm{m}^{3}\right)$ & $2.62 \pm 0.25^{\mathrm{b}}$ & $3.62 \pm 0.22^{\mathrm{a}}$ & $2.47 \pm 0.24^{\mathrm{a}}$ \\
FCR & $2.69 \pm 0.06^{\mathrm{a}}$ & $1.90 \pm 0.02^{\mathrm{c}}$ & $2.45 \pm 0.06^{\mathrm{b}}$ \\
\hline
\end{tabular}

Mean values with different superscript letters in the same row are significantly different $(\mathrm{P}<0.05)$. SGR, Specific Growth Rate, ADWG, Average Daily Weight Gain, and FCR, Feed Conversion Ratio. 
(Mukherjee, 1990). Circular holding facilities were found to be best for schooling fishes as salmon and milk fish. In Philippines, milk fish when put in square cages for breeding, injure themselves but this problem had been overcome by putting them in circular cages (Yu et al., 1979).

In the present study, most of the fish in circular cages, compared to fish in other shaped cages, came surface, were observed to appear in surface water, feed actively and move in circles surrounding the cage wall. In addition, a similar water quality values between cage and open pond water indicates that circular movement of the fish might have led to a vertical flow along the center line of the net cage resulting in a regular water flow between water within cage and open pond. Thus, the circular cage might have provided a less stressful environment to the test catfish species, M. cavasius, for their growth and survival.

\section{Length-weight relationship (LWRs)}

Logarithmic linear regression relationship of pooled data between total length and body weight of $M$. cavasius at square, circular and rectangular shaped cages over the study period was estimated respectively as $\log \mathrm{BW}=0.79$ $(\log T L)+0.23$ and $\log B W=0.92(\log$ $\mathrm{TL})+0.10$ and $\log \mathrm{BW}=0.74(\log \mathrm{TL})+$ 0.28 as shown in Fig. 3(a, b, c). The intercept "Ln a" were $0.23,0.10$ and 0.28 and slope "b" were $0.79,0.92$ and 0.74 for this species at square, circular and rectangular shaped cages respectively, indicating the pattern of negative allometric growth of this species at three cage shapes as $b<3$. It means that the fish was in favor to increase in length than in mass in cage environmental conditions. Earlier study

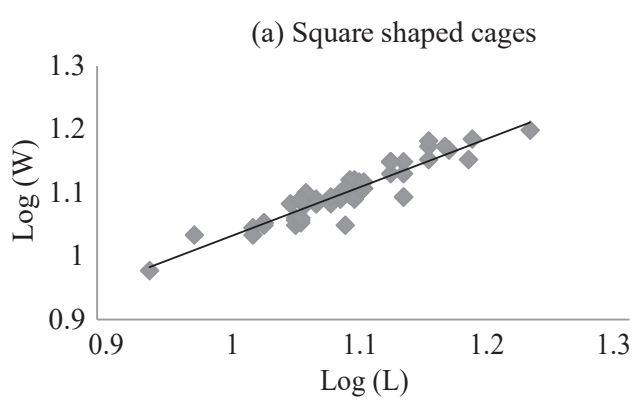

(b) Circular shaped cages

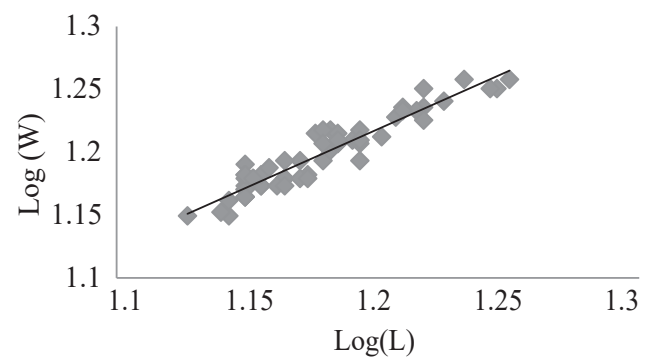

(c) Rectangular shaped cages

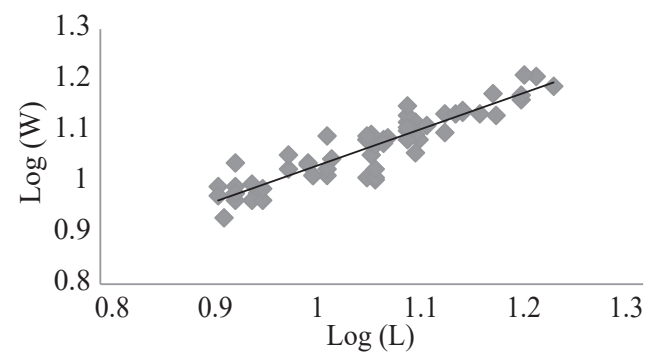

Fig. 3 Relationships (a, b, c) between log total length ( $L)$ and log body weight $(W)$ of $M$. cavasius reared in three different shaped cages.

reported on length-weight relationship on catfish (Pangasianodon gigas) performed by Paiboon and Mengumphan (2015) and showed negative growth pattern where $b$ values were 2.63 and 2.03. In all cases scattered diagrams showed almost linear relationship. The present study showed a negative allometric growth in gulsha reared cages irrespective of shapes. Chakraborty, et al. (2019) estimated length- 
Table 4. LWRs of M. cavasius in different shaped cages in pond condition

\begin{tabular}{lcccccc}
\hline \multicolumn{1}{c}{ Cage shape } & $\mathrm{n}$ & Relationships & Equations & $\mathrm{a}$ & $\mathrm{b}$ & $\mathrm{r}^{2}$ \\
\hline Square & 60 & TL vs. Wt. & $\mathrm{y}=0.79 \mathrm{x}+0.23$ & 0.23 & 0.79 & 0.86 \\
Circular & 60 & TL vs. Wt. & $\mathrm{y}=0.92 \mathrm{x}+0.10$ & 0.10 & 0.92 & 0.90 \\
Rectangular & 60 & TL vs. Wt. & $\mathrm{y}=0.74 \mathrm{x}+0.28$ & 0.28 & 0.74 & 0.85 \\
\hline
\end{tabular}

weight relationship on Mystus vittatus in two different aquatic habitats and found a negative allometric growth. With the regression coefficient (b) of 2.71, a negative allometric growth has been reported for M. cavasius from natural catch (Latif et al., 2018).

There is little significant difference of the "b" values of this species among three differently shaped cages. Although $\mathrm{b}<3$ at three different shaped cages but this species showed comparatively better growth at circular shaped cages than at square and rectangular shaped cages, perhaps the fish might get better environmental condition at circular shaped cages. The coefficient of determination ' $\mathrm{r}^{2}$. were 0.86 and 0.90 and 0.85 for square, circular and rectangular shaped cages respectively, suggesting that $86 \%$ and $90 \%$ and $85 \%$ of the variation in body weight was due to variation in total length in those three different shaped cages. The values of regression coefficient ${ }^{\prime} \mathrm{r}^{2}{ }^{\circ}=0.90$ indicate a good linear regression between length and weight of the species in circular shaped cages than square and rectangular shaped cages and also revealed that a comparatively good adjustment present between length and weight in circular shaped cages during the study period.

\section{Conclusions}

The results of the present study suggest that cage culture of a high valued small indigenous threatened catfish species, gulsha (M. cavasius) in pond is possible. Among the three typical shapes viz. rectangular, circular and square cage tested in this study, growth, survival and production of gulsha were the best in circular shaped cage. The fishes in cages exhibited a similar growth pattern in respect to length-weight relationships as they have been reported in the open pond and natural environment. Therefore, the cage culture of gulsha may be integrated with conventional open pond culture system as a potential option for increasing productivity of pond and availability of this threatened indigenous small fish species in the market and diet.

\section{Acknowledgements}

The authors sincerely thank the Research Management Wing (RMW) of Bangabandhu Sheikh Mujibur Rahman Agricultural University for the financial support to the research. The authors are also thankful to staff of the Department of Fisheries Biology and Aquatic Environment for their support in field and laboratory during the implementation of the study.

\section{References}

All Hosen, M. H., R. Pervin and S. I. M. Shahriar. 2017. Changes in growth performances, survival rate and water quality parameter of pond on different stocking density of Gulsha Tengra (Mystus cavasius) in a monoculture system. Int. J. Fish. Aqua. Studies. 5(6): 52-56.

Bhatnagar, A. and S. K. Garg. 2000. Causative factors of fish mortality in still water fish ponds under sub-tropical conditions. Aquacult.1(2): 91-96. 
Chakraborty, M., B. Mandal and A. Chanda. 2019. Seasonal Variation of Length-Weight Relationship of Mystus vittatus (Bloch, 1794) in Two Different Aquatic Habitat. Int. J. Fish. Aqua. Stud. 9(1): 1-13.

DoF. 2018. Yearbook of Fisheries Statistics of Bangladesh, 2017-18. Fisheries Resources Survey System (FRSS), Department of Fisheries, Bangladesh 129 P.

Fatema, K., M. F. Islam, N. Sultana and B. Saha. 2017. Effects of supplemented diets on the growth performance and nutrient contents of gulsha tengra, Mystus cavasius. Bangladesh J. Zool. 45(1): 61-71.

Golder, M. 1., W. N. Chowdhury and D. Griffiths. 1996. The economics of Pangasius sutchi cage culture in northwest Bangladesh using commercially available grow out feed, Presented at World Aquaculture'96, Bangkok, Thailand.

Hasan. 2014. Growth and production performance of stinging catfish (Heteropneustes fossilis) in different cage conditions. An MS dissertation Department of Fisheries, University of Dhaka, Dhaka -1000 , Bangladesh $80 \mathrm{P}$.

Kohinoor, A. H. M. and M. M. Rahman. 2015. Growth and production performances of threatened small indigenous fish Gulsha (Mystus cavasius) in cage system in the River Brahmaputra, Mymensingh, Bangladesh. Int. J. Fish. Aqua. Stud. 2(5): 180-183.

Kohinoor, A. H. M., M. M. Rahman, H. M. Moniruzzaman and S. C. Chakraborty. 2011-12. Production performance of pabda (Ompok pabda) and gulsha (Mystus cavasius) with GIFT strain (Oreochromis niloticus) in on-farm management system. Bangladesh J. Fish. Res. 15-16: 27-36.

Kohinoor, A. H. M. and M. M. Rahman. 2013. Preliminary study on the production of common carp cultured in freshwater river cages. Int. J. Agril. Res. Innov. Tech. 4(1): 24-27.

Latif, M., M. Z. Ullah, I. B. Minhas and S. Latif. 2018. Length-weight relationships of Mystus cavasius with special reference to body morphometric characters from river Chenab, Punjab, Pakistan. J. Ent. Zool. Stud. 6(2): 2418-2421.

Le Cren, E. D. 1951. The length-weight relationships and seasonal cycle in gonad weight and condition in the perch (Perca fluviatilis). J. Anim. Eco. 20: 201-209.

Mondal R. B., D. K. Jha, M. K. Shrestha, J. P. S. Rai and N. P. Pandit. 2014. Cage-pond integration of African catfish (Clarias gariepinus) and Nile tilapia (Oreochromis niloticus) with carps. Aquacult. Res. 45(8): 1311-1318.

Mondal, M. N. J., M. A. Shahin, M. Wahab, M. Asaduzzaman and Y. Yang. 2010. Comparison between cage and pond production of Thai Climbing Perch (Anabas testudineus) and Tilapia (Oreochromis niloticus) under three management systems. J. Bangladesh Agril. Univ. 8(2): 313-322.

Mukherjee, A. B. 1990. Site selection and structural design of netted enclosures of the National Seminar on Aquaculture development in India-problems and prospects, Trivandrum, India. Pp. 269-274.

Paiboon, P. and K. Mengumphan. 2015. Growth performance, length-weight relationship and condition factor of backcross and reciprocal hybrid catfish research in net cages. Int. J. Zool. Res. 11: 57-64.

Rahman, M. A., K. A. Habib, M. A. Hossain, S. M. O. Azad and M. Z. Rayhan. 2017. Impacts of stocking density and economic returns on the cage culture of stinging catfish, Heteropneustes fossilis. Int. J. Fish. Aqua. Stud. 5(4): 198-201.

Soltan, M. 2016. Cage culture of freshwater fish. https://www.researchgate.net/ publication/294087263; DOI: 10.13140/ RG.2.1.4802.2803.

Yu, O. K., A. T. Vizcarra and H. S. Sitoy. 1979. Development of circular floating cages for milkfish brood-stock at the SEAFDEC Aquaculture Department, In Proceedings of the International Workshop on Pen Cage Culture of Fish, Philippines Pp. 107-117. 